\title{
Perencanaan Strategis Sistem Informasi untuk Optimalisasi Layanan Sekolah Menggunakan Ward and Peppard
}

\author{
Ibnur Rusi $^{[1]^{*}}$, Ferdy Febriyanto ${ }^{[2]^{*}}$ \\ Jurusan Sistem Informasi ${ }^{[1][2]}$ \\ Universitas Tanjungpura \\ Pontianak, Indonesia \\ ibnurrusi@sisfo.untan.ac.id ${ }^{[1]}$, ferdyf@sisfo.untan.ac.id ${ }^{[2]}$
}

\begin{abstract}
The use of technology and information systems is an obligation that must be applied by every agency or organization to simplify and optimize operational implementation. Many agencies are actively using information systems so that the agency's performance can run well, systematically, and controlled, which will impact the credibility of their agency. A good information system can be created because of good planning. Strategic planning of information systems allows producing a good information system. This is because the output produced is in the form of strategic plans and documents that methodically describe the needs of information systems. Torsina Private Vocational School is a vocational school that seeks to implement information systems in every operation to improve schools' services. Therefore, strategic planning is needed in the development of IS/IT at Torsina Private Vocational Schools so that the implementation of information systems becomes more controlled and on target. IS/IT strategic planning in this study uses the Ward and Peppard model, while the analytical tools used are Critical Success Factors (CSF's), SWOT Analysis, Value Chain, and McFarlans Strategic Grid. The existence of an analytical tool is used to support the Ward and Peppard model to determine the internal and external environmental conditions of the organization. The results of this study are strategic planning of information systems at Torsina Private Vocational Schools in the form of business strategy, IT strategy, IS/IT management strategy, and an information system portfolio that is mapped based on the level of importance.
\end{abstract}

Keywords - Strategic Planning, Information Systems, Ward and Peppard.

\footnotetext{
Abstrak- Penggunaan teknologi dan sistem informasi menjadi suatu kewajiban yang harus diterapkan oleh setiap instansi atau organisasi untuk mempermudah dan mengoptimalkan pelaksanaan operasional. Banyak instansi giat memanfaatkan sistem informasi agar kinerja instansi dapat berjalan dengan baik, sistematis, dan terkontrol yang hasil akhirnya akan berdampak pada kredibilitas instansi mereka. Sistem informasi yang baik dapat tercipta karena adanya perencanaan yang baik. Perencanaan strategis sistem informasi memungkinkan untuk menghasilkan sistem informasi yang baik, hal ini dikarenakan output yang dihasilkan berupa rencana strategis dan dokumen yang menggambarkan secara metodis kebutuhan sistem informasi. SMK Swasta Torsina merupakan
}

sekolah kejuruan yang berupaya menerapakan sistem informasi pada setiap operasional guna meningkatkan layanan di sekolah. Diperlukan perencanaan strategis dalam pengembangan SI/TI pada SMK Swasta Torsina agar implementasi sistem informasi menjadi lebih terkontrol dan tepat sasaran. Perencanaan strategis SI/TI pada penelitian ini menggunakan model Ward and Peppard, sedangkan alat analisis yang digunakan adalah Critical Success Factors (CSF's), SWOT Analysis, Value Chain, dan McFarlans Strategic Grid. Adanya alat analisis digunakan sebagai pendukung model Ward and Peppard untuk mengetahui kondisi lingkungan internal dan eksternal organisasi. Hasil penelitian ini adalah perencanaan strategis sistem informasi pada SMK Swasta Torsina berupa business strategy, IT strategy, IS/IT management strategy, dan portofolio sistem informasi yang dipetakan berdasarkan tingkat kepentingan.

Kata Kunci-Perencanaan Strategis, Sistem Informasi, Ward and Peppard.

\section{PENDAHULUAN}

Teknologi dan Sistem Informasi pada era modern ini berkembang semakin pesat. Sistem Informasi menjadi suatu kewajiban yang harus digunakan oleh setiap instansi atau organisasi untuk mempermudah dan mengoptimalkan pelaksanaan operasional yang mereka lakukan. Instansi atau organisasi akan terus berupaya semaksimal mungkin agar proses dan alur kerja yang ada pada instansi mereka menjadi lebih efektif dan efisien dengan pemanfaatan sistem informasi didalamnya. Melalui pertimbangan ini, banyak instansi yang semakin giat membuat atau memanfaatkan sistem informasi agar kinerja instansi dapat berjalan dengan baik, sistematis, dan terkontrol yang hasil akhirnya akan berdampak pada kredibilitas instansi mereka.

Sistem informasi yang baik dapat tercipta karena adanya perencanaan yang baik. Perencanaan strategis sistem informasi memungkinkan untuk menghasilkan sistem informasi yang baik, karena output yang dihasilkan adalah rencana strategi dan dokumen yang menggambarkan secara metodis kebutuhan sistem informasi saat ini dan masa depan, sesuai dengan yang diinginkan berdasar pada visi, misi, dan tujuan instansi [1]. Identifikasi portofolio aplikasi atau sistem informasi pada perencanaan strategis juga dapat mendukung instansi dalam 
merealisasikan tujuan bisnisnya. Business value yang menjadi salah satu indikator keberhasilan suatu instansi akan lebih mudah didapatkan dengan adanya perencanaan dan pengelolaan yang strategis terhadap sistem informasi yang ada dan akan diimplementasikan. Selain itu, dengan adanya perencanaan strategi sistem informasi, instansi dapat memitigasi permasalahan-permasalahan yang dihadapi berkaitan dengan pengelolaan dan penerapan sistem informasi [2]. Berbanding terbalik dengan instansi yang tidak memiliki perencanaan matang mengenai strategi sistem informasi, ketiadaan perencanaan akan mengakibatkan suatu instansi tidak memiliki skala prioritas dalam pengadaan teknologi atau sistem informasi, dan akhirnya akan berdampak pada penurunan produktivitas instansi [3].

Ward and Peppard merupakan metode dalam perencanaan strategis Sistem Informasi/Teknologi Informasi (SI/TI). Output dari metode ini berupa portofolio aplikasi yang diperlukan saat ini dan masa yang akan datang, dengan adanya portofolio ini diharapkan instansi dapat meningkatkan efektifitas dan efisiensi kinerja, sehingga visi, misi, dan tujuan instansi dapat tercapai. Proses untuk menghasilkan output melalui analisis-analisis lingkungan yang ada di internal dan eksternal instansi, seperti lingkungan internal bisnis (internal business environment), lingkungan internal SI/TI (internal IS/IT environment), lingkungan eksternal bisnis (external business environment), dan lingkungan eksternal SI/TI (external IS/IT environment) [4]. Sedangkan untuk mendukung analisis lingkungan internal dan eksternal dapat diketahui melalui beberapa analisis, seperti Critical Success Factor's (CSFs), SWOT Analysis, McFarlan's Strategic Grid, dan Value Chain Analysis.

Sekolah merupakan institusi pendidikan yang memiliki tujuan untuk membantu dalam proses pembelajaran, yang dilaksanakan secara sistematis guna memberikan pengetahuan dan wawasan tambahan kepada peserta didik [5]. Sebagai institusi atau instansi pendidikan yang ada pada era modern saat ini, sekolah harus siap menghadapi tuntutan dan perkembangan teknologi dan sistem informasi. Diperlukan perencanaan strategis yang matang khususnya pada penerapan sistem informasi agar sekolah dapat memaksimalkan operasional kerja dan proses pembelajaran yang mereka lakukan.

Sekolah Menengah Kejuruan (SMK) Swasta Torsina merupakan salah satu sekolah kejuruan yang berupaya menerapkan sistem informasi dan teknologi informasi pada setiap operasionalnya guna mengoptimalkan layanan di sekolah. Sebagai sekolah kejuruan yang hadir di era teknologi seperti saat ini, SMK Swasta Torsina juga harus dapat menyesuaikan diri dengan melakukan peningkatan kinerja sekolah, diantaranya melalui pemanfaatan teknologi dan sistem informasi. Tujuan dari penelitian ini adalah untuk memberikan perencanaan strategis sistem informasi pada SMK Swasta Torsina berupa business strategy, IT strategy, IS/IT management strategy, dan portofolio sistem informasi yang dipetakan berdasarkan tingkat kepentingannya, sehingga SMK Torsina dapat tetap terus eksis dan memberikan pelayanan yang optimal kepada seluruh stakeholder yang ada.

Penelitian serupa berkaitan dengan perencanaan strategis
SI/TI pernah dilakukan diantaranya adalah [6][7][8][9][10] Pada penelitian [6] dan [10] menggunakan model Ward and Peppard, dan alat analisis yang digunakan yaitu PEST, Value Chain, dan McFarlan's Strategic Grid [6], sedangkan penelitian [10] menggunakan Value Chain, Five Force, dan McFarlan's Stretegic Grid. Perbedaan dengan penelitian ini adalah pada alat analisis yang digunakan. Penelitian ini menggunakan alat analisis CSF's, analisis SWOT, analisis McFarlan's, dan analisis Value Chain. Penelitian [7] model perencanaan yang digunakan yaitu Zachman Framework dengan Value Chain dan McFarlan's sebagai alat analisis. Perbedaan dengan penelitian ini selain pada model perencanaan yang digunakan, alat analisis pada penelitian [7] juga lebih sedikit daripada penelitian ini. Penelitian [8] dan [9] menggunakan Enterprise Architecture Planning (EAP) sebagai model perencanaan SI/TI, sedangkan alat analisisnya pada penelitian [8] yaitu Value Chain dan SWOT. Pada penelitian [9] menggunakan Value Chain. Perbedaan penelitian [8] dan [9] dengan penelitian ini adalah pada model perencanaan strategis SI/TI dan jumlah alat analisis yang digunakan. Dari penelitian [6][7][8][9][10] yang menjadi acuan penelitian ini, terdapat beberapa perbedaan baik dari model perencanaan strategis SI/TI maupun alat analisisnya. Pada penelitian ini pula disajikan teori model perencanaan strategis dan alat analisis yang digunakan, kerangka kerja metode penelitian, serta hasil dan pembahasan yang tersusun secara sistematis, sehingga dapat menjadi rujukan dan agar lebih mudah dipahami.

\section{TINJAUAN PUSTAKA}

\section{A. Perencanaan Strategis}

Perencanaan strategis merupakan perencanaan jangka panjang dari suatu instansi atau organisasi yang bersifat menyeluruh, berisi instruksi dan cara dalam pengelolaan sumber daya untuk mencapai tujuan organisasi dalam jangka waktu tertentu [11]. Dalam perencanaan strategis perlu dilakukan penyusunan dan pemilihan tujuan dan langkahlangkah apa saja yang harus diprioritaskan, dengan mempertimbangkan keadaan saat ini dan kemungkinan perkembangan yang akan terjadi di masa yang akan datang. Perencanaan strategis juga berkaitan dengan alat-alat apa saja yang akan digunakan untuk mencapai tujuan dari suatu organisasi [12].

\section{B. Ward and Peppard}

Ward and Peppard merupakan model yang digunakan dalam perencanaan strategis Sistem Informasi/Teknologi Informasi (SI/TI). Tujuan dari metode ini adalah untuk menghasilkan portofolio aplikasi atau sistem informasi yang dapat digunakan oleh perusahaan. Pada metode Ward and Peppard terdiri dari tahapan input dan output. Tahapan input meliputi internal business environment, internal IS/IT environment, external business environment, external IS/IT environment. Internal dan external business environment merupakan kondisi lingkungan bisnis yang ada di dalam dan di luar perusahaan, sedangkan internal dan external IS/IT environment merupakan kondisi atau keberadaan SI/TI yang ada di dalam dan di luar perusahaan. Adapun output dari Ward and Peppard meliputi business strategy, IS/IT management strategy, IT strategy, current dan/atau future application 
portofolio. Business strategy mencakup keseluruhan strategi bisnis yang dapat diterapkan dalam perencanaan strategis, IS/IT management strategy dan IT strategy berkaitan dengan pengelolaan strategi dalam penerapan SI dan TI untuk organisasi, sedangkan current dan/atau future application portofolio merupakan kebutuhan aplikasi yang dapat menunjang kinerja organisasi [13].

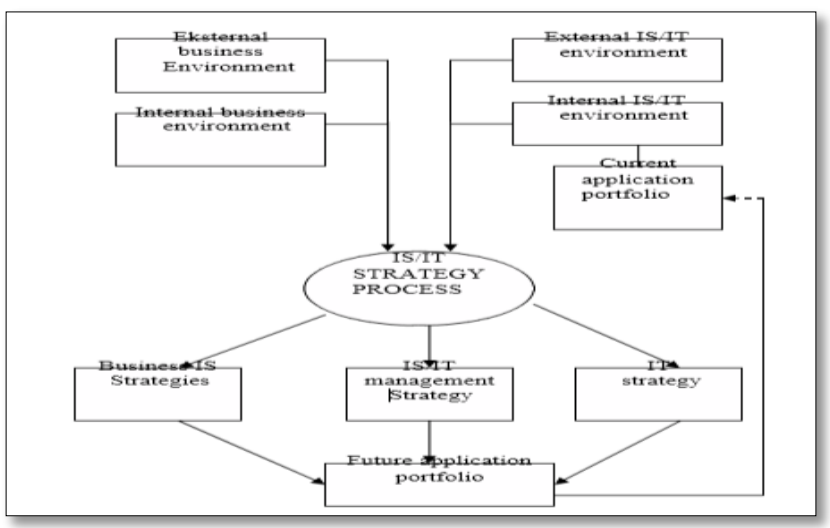

Gambar 1. Perencanaan Strategis SI/TI Ward and Peppard

\section{Critical Success Factors (CSFs)}

Critical Success Factors merupakan analisis yang berkaitan dengan ketetapan suatu organisasi dan lingkungan organisasi yang memiliki pengaruh terhadap keberhasilan atau kegagalan organisasi [14]. Objektif organisasi berpengaruh besar terhadap ketetapan faktor-faktor kesuksesan, karena CSFs baru dapat ditetapkan jika identifikasi objektif dari organisasi telah selesai dilakukan. Pada perencanaan strategis SI/TI, CSFs dapat digunakan sebagai alat untuk menganalisis strategi-strategi berdasarkan tujuan organisasi sehingga dapat menjadi kunci sukses dalam pelaksanaan operasional yang dilakukan.

\section{SWOT Analysis}

SWOT adalah singkatan dari Strength, Weakness, Opportunity, dan Threats merupakan metode analisis dalam perencanaan strategis untuk mengetahui dan mengevaluasi kekuatan, kelemahan, peluang, dan ancaman pada suatu organisasi [15]. Kekuatan (strength) dan kelemahan (weakness) merupakan faktor yang berasal dari internal perusahaan, sedangkan peluang (opportunity) dan ancaman (threats) datang dari ekternal perusahaan. Pada analisis SWOT terdapat matriks yang digunakan untuk mengetahui keterkaitan antara 4 faktor tersebut, yang disebut dengan strategi SO (Strength-Opportunity), strategi WO (WeaknessOpportunity), strategi ST (Strength-Threats), dan strategi WT (Weakness-Threats).

\begin{tabular}{|l|c|c|}
\hline INTERNAL & $\begin{array}{c}\text { Strengths } \\
\text { (S) }\end{array}$ & $\begin{array}{c}\text { Weaknesses } \\
\text { (W) }\end{array}$ \\
\hline Opportunities (O) & $\begin{array}{c}\text { Strategi S0 } \\
\text { Mengembangkan strategi } \\
\text { dengan memanfaatkan kekuatan } \\
\text { (S) untuk memperoleh manfaat } \\
\text { dari peluang (O) yang tersedia }\end{array}$ & $\begin{array}{c}\text { Strategi WO } \\
\text { Mengembangkan strategi } \\
\text { dengan memanfaatkan peluang } \\
\text { (O) untuk mengatasi kelemahan } \\
\text { (W) yang dimiliki }\end{array}$ \\
\hline Threats (T) & $\begin{array}{c}\text { Strategi ST } \\
\text { Mengembangkan strategi dengan } \\
\text { memanfaatkan kekuatan (S) untuk } \\
\text { menghindari ancaman (T) vang ada }\end{array}$ & $\begin{array}{c}\text { Strategi WT } \\
\text { Mengembangkan strategi dalam } \\
\text { mengurangi kelemahan (W) dan } \\
\text { menghindari ancaman (T) }\end{array}$ \\
\hline
\end{tabular}

Gambar 2. Matriks SWOT Analysis

\section{E. McFarlan's Strategic Grid}

McFarlan's Strategic Grid digunakan untuk memetakan aplikasi atau sistem informasi yang perlu digunakan oleh organisasi dengan melihat peranannya bagi organisasi tersebut. Pemetaan pada McFarlan's Strategic Grid terdiri dari 4 kuadran yaitu strategic, high potential, key operational, dan support. [16].

\begin{tabular}{|l|l|}
\hline $\begin{array}{l}\text { Key Operational } \\
\text { Aplikasi yang penting untuk mendukung } \\
\text { operasional organisasi saat ini }\end{array}$ & $\begin{array}{l}\text { Strategic } \\
\text { Aplikasi yang penting untuk } \\
\text { kesuksesan masa depan }\end{array}$ \\
\hline $\begin{array}{l}\text { Support } \\
\text { Aplikasi yang dapat meningkatkan } \\
\text { performansi dan manajemen, tetapi tidak } \\
\text { kritis untuk operasional oraganisasi saat } \\
\text { ini }\end{array}$ & $\begin{array}{l}\text { High Potential } \\
\text { dalam strategi kedepan }\end{array}$ \\
\hline
\end{tabular}

Gambar 3. Pemetaan Strategi McFarlan's

\section{F. Value Chain Analysis}

Value Chain Analysis merupakan alat untuk strategic analysis yang digunakan untuk mengoptimalkan value bagi produk dan pengguna, serta menganalisis hubungan organisasi dengan stakeholder terkait [17]. Pada Value Chain Analysis terdapat 2 aktivitas yang harus dilakukan organisasi, yaitu aktivitas utama (primary activity) dan aktivitas pendukung (support activity).

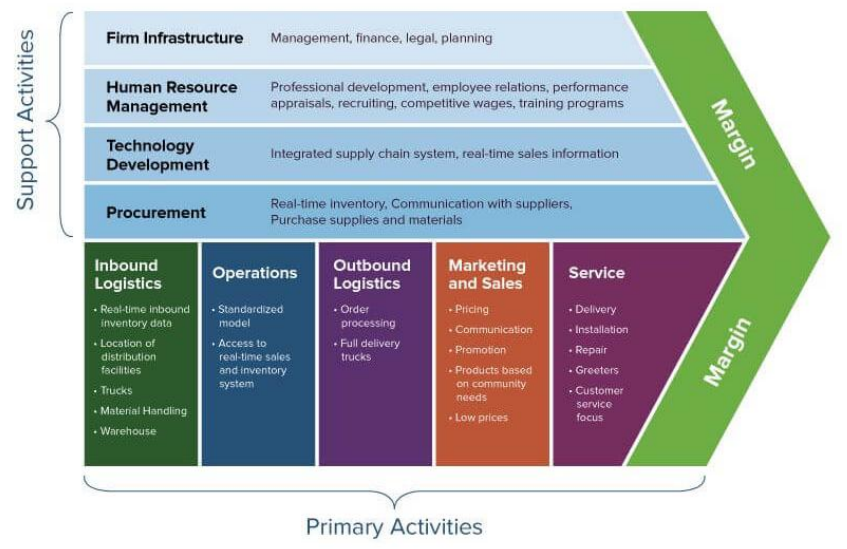

Gambar 4. Value Chain Analysis 


\section{METODE PENELITIAN}

Metode penelitian yang digunakan pada penelitian ini adalah pendekatan kualitatif. Pendekatan kualitatif merupakan pendekatan yang dilakukan menggunakan aspek kencenderungan, tidak bersifat perhitungan numerik, melainkan berupa deskripsi situasi dan deep interview [18].

Teknik pengumpulan data melalui wawancara dan observasi. Wawancara dilakukan kepada Kepala Sekolah (Kepsek), sedangkan observasi melihat secara langsung kondisi dan keadaan di lapangan. Guna mempermudah dalam melakukan penelitian, peneliti membuat kerangka kerja yang dapat menjadi acuan peneliti agar langkah-langkah yang dilakukan menjadi lebih sistematis dan terarah. Berikut ini merupakan kerangka kerja penelitian.

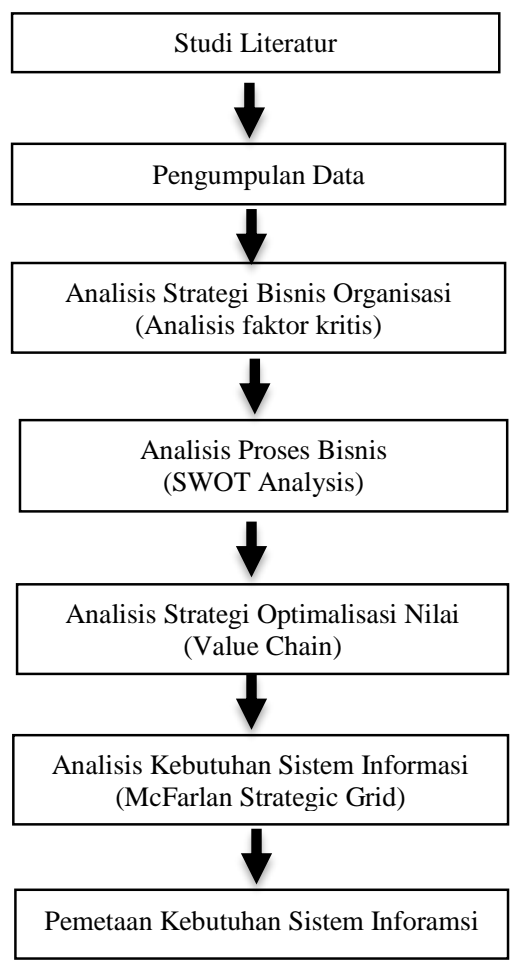

Gambar 5. Kerangka Kerja Penelitian

Kerangka kerja pada penelitian ini terdiri dari beberapa tahap. Pertama adalah pengumpulan data. Data pada tahap ini berupa informasi visi, misi, tujuan, sasaran organisasi, sumber daya, dan pengelolaan bagian-bagian yang ada di organisasi tersebut, termasuk ketersediaan teknologi dan informasi. Tahap kedua yaitu menganalisis faktor-faktor kritis untuk mencapai kesuksesan dengan mengacu pada visi, misi, sasaran dan tujuan organisasi menggunakan CSFs. Tahap ketiga, melakukan analisis kekuatan dan kelemahan dari internal sekolah yang dapat digunakan untuk memanfaatkan peluang dan menghadapi ancaman dari pihak eksternal, metode yang digunakan adalah SWOT Analysis. Setelah diketahui kekuatan, kelemahan, peluang, dan ancaman, kemudian dibuat strategi tindakan menggunakan matriks SWOT. Tahap keempat melakukan analisis strategi optimasi nilai menggunakan value chain analysis. Tujuan dari tahap ini adalah untuk memetakan aktivitas utama dan aktivitas pendukung yang perlu dilakukan, agar strategi yang dibuat menjadi lebih terstrukur dan maksimal. Tahap terakhir yaitu menganalisis kebutuhan sistem informasi yang diperlukan oleh sekolah, dan kemudian memetakannya berdasarkan matriks McFarlan Strategic Grid.

Penggunaan beberapa metode seperti CSFs, SWOT Analysis, Value Chain Analysis, dan McFarlan Strategic Grid pada penelitian ini adalah sebagai pendukung dari Ward and Peppard, yaitu untuk menganalisis lingkungan internal dan eksternal organisasi. Sehingga dengan menggunakan metodemetode tersebut, Ward and Peppard akan lebih mudah diimplementasikan.

\section{HASIL DAN PEMBAHASAN}

Hasil dan pembahasan menjelaskan temuan yang didapatkan di tempat penelitian, kemudian dilakukan tindakan analisis berdasarkan temuan-temuan tersebut. Berdasarkan hasil wawancara dan observasi, bahwa SMK Swasta Torsina belum memiliki perencanaan strategis sistem informasi. Sedangkan untuk pengelolaan SI/TI masih belum ada bagian khusus yang fokus menangani SI/TI di sekolah. Sehingga untuk meningkatkan kinerja, perlu dibuat perencanaan strategis SI/TI untuk SMK Swasta Torsina. Untuk mengetahui kondisi lingkungan internal dan eksternal organisasi pada perencanaan strategis SI/TI menggunakan analisis CSF's, SWOT, dan Value Chain, sedangkan kondisi lingkungan SI/TI internal dan eksternal menggunakan McFarlan Strategic Grid.

\section{A. Critical Success Factors (CSF's)}

Analisis CSF's didasarkan pada hasil wawancara dan dokumen-dokumen yang ada seperti tujuan dan sasaran sekolah. Hasil dari CSF's adalah seperti tabel berikut.

TABEL 1. CRITICAL SUCCESS FACTORS ANALYSIS

\begin{tabular}{|c|c|c|c|}
\hline No & Tujuan Utama & CSF's & $\begin{array}{l}\text { Kebutuhan } \\
\text { Informasi }\end{array}$ \\
\hline 1 & $\begin{array}{l}\text { Sekolah memiliki } \\
\text { pengelolalan data } \\
\text { akademik siswa }\end{array}$ & $\begin{array}{l}\text { Menyediakan data } \\
\text { pengelolaan } \\
\text { akademik siswa } \\
\text { berbasis komputer }\end{array}$ & $\begin{array}{l}\text { Data mengenai } \\
\text { pengelolaan akademik } \\
\text { siswa }\end{array}$ \\
\hline 2 & $\begin{array}{l}\text { Terselenggaranya } \\
\text { dengan baik } \\
\text { Kegiatan Belajar } \\
\text { Mengajar (KBM) }\end{array}$ & $\begin{array}{l}\text { Menyediakan bahan } \\
\text { ajar dan fasilitas } \\
\text { untuk mendukung } \\
\text { KBM }\end{array}$ & $\begin{array}{l}\text { Data mengenai KBM } \\
\text { dan kurikulum sekolah }\end{array}$ \\
\hline 3 & $\begin{array}{l}\text { Memiliki guru } \\
\text { yang berkompeten }\end{array}$ & $\begin{array}{l}\text { Menyediakan guru } \\
\text { yang memiliki } \\
\text { kompetensi / atau } \\
\text { bersertifikat }\end{array}$ & $\begin{array}{l}\text { Data guru yang berisi } \\
\text { kompetensi/keahlian }\end{array}$ \\
\hline 4 & $\begin{array}{l}\text { Menghasilkan } \\
\text { lulusan/alumni } \\
\text { yang dapat } \\
\text { langsung bekerja }\end{array}$ & $\begin{array}{l}\text { Menjalin kerjasama } \\
\text { dengan perusahaan } \\
\text { yang mencari } \\
\text { lulusan SMK }\end{array}$ & $\begin{array}{l}\text { Data alumni yang } \\
\text { telah bekerja }\end{array}$ \\
\hline 5 & $\begin{array}{l}\text { Meningkatkan } \\
\text { persentase jumlah } \\
\text { peserta didik }\end{array}$ & $\begin{array}{l}\text { Memperbesar } \\
\text { volume penerimaan } \\
\text { dan memperluas } \\
\text { promosi }\end{array}$ & $\begin{array}{l}\text { Data peserta didik / } \\
\text { siswa }\end{array}$ \\
\hline 6 & $\begin{array}{l}\text { Memiliki } \\
\text { pengelolaan yang } \\
\text { baik pada sarana } \\
\text { dan prasarana }\end{array}$ & $\begin{array}{l}\text { Menginventarisir } \\
\text { sarana dan } \\
\text { prasarana }\end{array}$ & $\begin{array}{l}\text { Data sarana dan } \\
\text { prasarana }\end{array}$ \\
\hline 7 & $\begin{array}{l}\text { Memiliki } \\
\text { manajerial yang } \\
\text { baik dalam }\end{array}$ & $\begin{array}{l}\text { Mencatat setiap } \\
\text { transaksi dalam } \\
\text { mengelola }\end{array}$ & $\begin{array}{l}\text { Data dan informasi } \\
\text { keuangan dan } \\
\text { pembiayaan }\end{array}$ \\
\hline
\end{tabular}




\begin{tabular}{|c|c|c|c|}
\hline & $\begin{array}{l}\text { keuangan dan } \\
\text { pembiayaan }\end{array}$ & $\begin{array}{l}\text { keuangan dan } \\
\text { pembiayaan }\end{array}$ & \\
\hline 8 & $\begin{array}{l}\text { Memiliki } \\
\text { hubungan erat } \\
\text { antara orang tua } \\
\text { siswa dengan } \\
\text { sekolah }\end{array}$ & $\begin{array}{l}\text { Melakukan sharing } \\
\text { dan pertemuan } \\
\text { dengan orangtua } \\
\text { siswa }\end{array}$ & $\begin{array}{l}\text { Data lengkap siswa, } \\
\text { orangtua, dan kegiatan } \\
\text { sekolah }\end{array}$ \\
\hline 9 & $\begin{array}{l}\text { Memiliki data } \\
\text { yang lengkap } \\
\text { mengenai } \\
\text { organisasi dan } \\
\text { manajemen }\end{array}$ & $\begin{array}{l}\text { Melakukan } \\
\text { pengelolaan data } \\
\text { manajerial dan } \\
\text { peningkatan } \\
\text { aksesibilitas }\end{array}$ & $\begin{array}{l}\text { Data organisasi dan } \\
\text { manajemen sekolah }\end{array}$ \\
\hline
\end{tabular}

\section{B. SWOT Analysis}

Penggunaan analisis SWOT bertujuan untuk mengetahui kekuatan, kelemahan, peluang, dan ancaman yang ada. Kekuatan dan kelemahan berasal dari internal sekolah, sedangkan peluang dan ancaman bersumber dari eksternal sekolah yang bisa menjadi penghambat tercapainya tujuan dari sekolah. Berdasarkan analisis SWOT, dibuat alternatifalternatif strategi menggunakan matriks SWOT, yaitu strategi S-O (Strengths-Opportunities), strategi W-O (WeaknessesOpportunities), strategi S-T (Strenghts-Threats), dan strategi W-T (Weaknesses-Threats). Tabel 2 merupakan matriks SWOT.

TABEL 2. MATRIKS SWOT ANALYSIS

\begin{tabular}{|c|c|c|}
\hline erne & Strengths $(S)$ & Weaknesses (W) \\
\hline $\begin{array}{c}\text { Opportunities } \\
(\mathrm{O})\end{array}$ & $\begin{array}{l}\text { Strategi S-O } \\
\text { 1. Menerapkan TIK } \\
\text { sebagai penunjang } \\
\text { dalam proses } \\
\text { pembelajaran dan } \\
\text { kreativitas } \\
\text { 2. Mengembangkan } \\
\text { citra/image sekolah } \\
\text { melalui serangkaian } \\
\text { program/kegiatan } \\
\text { dengan pemanfaatan } \\
\text { fasilitas dan } \\
\text { prasarana sekolah } \\
\text { 3. Mengembangkan } \\
\text { hubungan kerja sama } \\
\text { dengan perusahaan } \\
\text { potensial, terkait } \\
\text { jurusan di sekolah } \\
\text { 4. Meningkatkan daya } \\
\text { kreatifitas, inovasi } \\
\text { dan keterampilan } \\
\text { softskill murid yang } \\
\text { relevan dengan dunia } \\
\text { kerja }\end{array}$ & 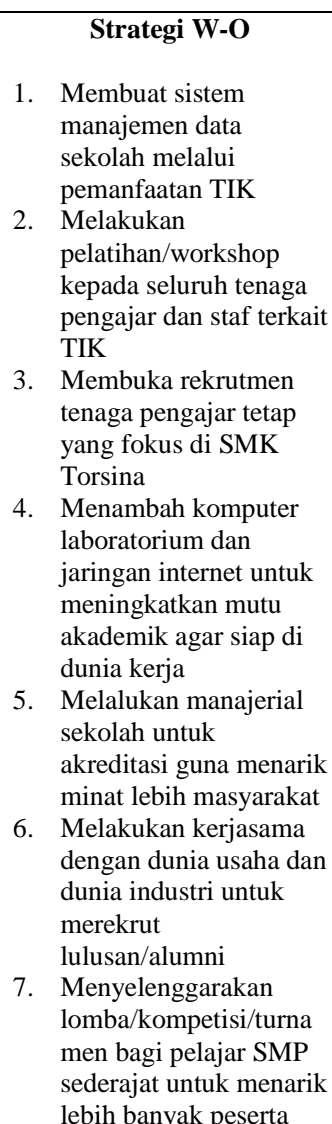 \\
\hline
\end{tabular}

\begin{tabular}{|c|c|c|}
\hline & & $\begin{array}{ll}\text { didik baru } \\
\text { 8. } & \text { Membuat sistem } \\
\text { manajemen keuangan } \\
\text { untuk pengelolaan } \\
\text { keuangan sekolah } \\
\text { 9. } \begin{array}{l}\text { Membuat sistem } \\
\text { pengelolaan sarana dan } \\
\text { prasarana sekolah }\end{array} \\
\end{array}$ \\
\hline Threats $(T)$ & \begin{tabular}{l}
\multicolumn{1}{c}{ Strategi S-T } \\
1. Adanya maintenance \\
terhadap brand/citra \\
sekolah \\
2. Memastikan selalu \\
adanya \\
pengembangan dan \\
inovasi terhadap \\
setiap bidang \\
jurusan, baik secara \\
akademis maupun \\
nonakademis \\
3. Mengaplikasikan SI \\
dalam operasional \\
sekolah
\end{tabular} & \begin{tabular}{ll} 
& \multicolumn{1}{c}{ Strategi W-T } \\
1. & $\begin{array}{l}\text { Maintenance terhadap } \\
\text { kualitas tenaga } \\
\text { pengajar. }\end{array}$ \\
2. & $\begin{array}{l}\text { Maintenance terhadap } \\
\text { akreditasi dan kualitas } \\
\text { sekolah }\end{array}$ \\
3. & Melakukan \\
maintenance dan & upgrading rutin \\
terhadap manajemen SI \\
sekolah untuk dapat \\
berjalan sesuai dengan \\
kebutuhan. \\
4. Memberikan pelatihan \\
softskill kepada siswa \\
yang akan lulus \\
sekolah agar lebih \\
mudah diterima di \\
dunia kerja
\end{tabular} \\
\hline
\end{tabular}

\section{Value Chain Analysis}

Analisis Value Chain bertujuan untuk menentukan atau memilih aktivitas-aktivitas apa saja yang dapat memberikan nilai kepada organisasi, kemudian mengoptimalkan aktivitas tersebut agar dapat memberikan nilai tambah bagi organisasi. Pada analisis value chain terdapat aktivitas utama dan aktivitas pendukung yang dapat menjadi rencana strategis dalam pengembangan sistem informasi. Berikut ini adalah analisis value chain pada SMK Swasta Torsina.

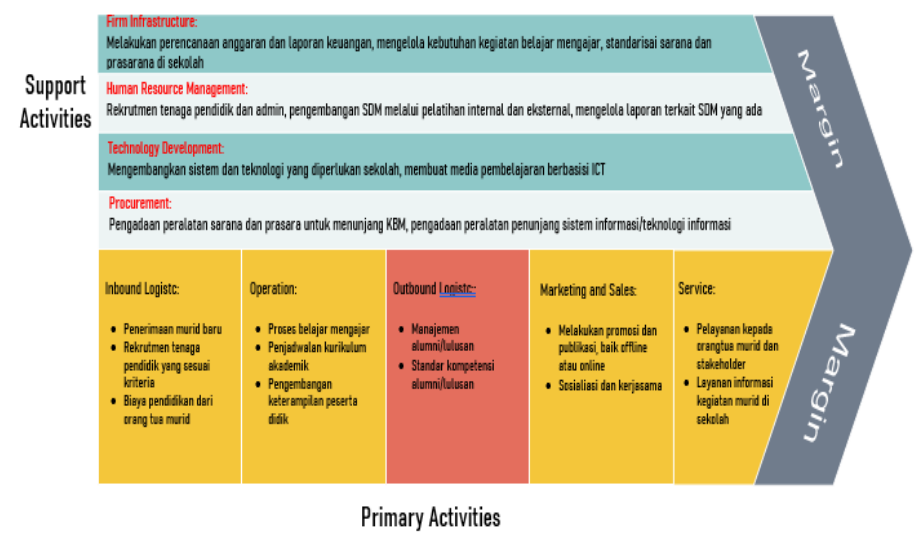

Gambar 6. Analisis Value Chain SMK Swasta Torsina

\section{Primary Activities (Aktivitas Utama)}

Aktivitas utama pada value chain analysis SMK Swasta Torsina terdiri dari beberapa bagian. Berikut ini yang menjadi aktivitas utama untuk perencanaan strategis SI/TI SMK Swasta Torsina. 
a. Inbound Logistic

- Penerimaan murid baru

- Rekrutmen tenaga pendidik yang sesuai kriteria

- Biaya pendidikan dari orang tua murid

b. Operation

- Proses belajar mengajar

- Penjadwalan kurikulum akademik

- Pengembangan keterampilan peserta didik

c. Outound Logistic

- Manajemen alumni/lulusan

- Standar kompetensi alumni/lulusan

d. Marketing and Sales

- Melakukan promosi dan publikasi, baik offline atau online

- Sosialiasi dan kerjasama

e. Service

- Pelayanan kepada orangtua murid dan stakeholder

- Layanan informasi kegiatan murid di sekolah

2. Support Activities (Aktivitas Pendukung)

Sedangkan yang menjadi aktivitas pendukung untuk perencanaan strategis SI/TI SMK Swasta Torsina melalui value chain analysis adalah sebagai berikut.

a. Firm Infrastructure

- Melakukan perencanaan anggaran dan laporan keuangan

- Mengelola kebutuhan kegiatan belajar mengajar

- Standarisasi sarana dan prasarana di sekolah

b. Human Resource Management

- Rekrutmen tenaga pendidik dan admin

- Pengembangan SDM melalui pelatihan internal dan eksternal

- Mengelola laporan terkait SDM yang ada

c. Technology Development

- Mengembangkan sistem dan teknologi yang diperlukan sekolah

- Membuat media pembelajaran berbasis ICT

d. Procurement

- Pengadaan peralatan sarana dan prasarana untuk menunjang KBM

- Pengadaan peralatan penunjang sistem informasi/teknologi informasi

\section{McFarlan's Strategic Grid}

McFarlan's Strategic Grid bertujuan untuk membuat pemetaan dan portofolio sistem informasi yang diperlukan dengan mempertimbangkan peran dan kepentingan sistem tersebut bagi kesuksesan operasional organisasi. Sebelum melakukan pemetaan, terlebih dahulu dilakukan observasi ketersediaan, identifikasi kebutuhan sistem, kemudian menganalisis kebutuhan sistem tersebut bagi kepentingan organisasi menggunakan CSF's, SWOT, dan Value Chain Analysis. McFarlan's Strategic Grid terdiri dari 4 kuadran, yaitu strategic, high potential, support, dan key operational. Berdasarkan hasil analisis didapatkan kebutuhan sistem informasi atau aplikasi yang dapat diterapkan di SMK Swasta Torsina.

TABEL 3. PEMETAAN SISTEM INFORMASI MCFARLAN'S

\begin{tabular}{|l|l|}
\hline \multicolumn{1}{|c|}{ Key Operational } & \multicolumn{1}{|c|}{ Strategic } \\
\hline SI Penerimaan Siswa Baru & SI Akademik \\
SI Kepegawaian & E-Learning \\
SI Organisasi dan Manjemen & Website Sekolah \\
\hline \multicolumn{1}{|c|}{ Support } & \multicolumn{1}{c|}{ High Potential } \\
\hline SI Kerjasama Mitra & Tracer Study \\
SI Orang Tua Murid & SI Keuangan dan Pembiayaan \\
& SI Sarana dan Prasarana \\
\hline
\end{tabular}

1. Key Operational merupakan sistem informasi yang penting saat ini sehingga dapat menciptakan nilai tambah organisasi, yaitu dengan melalui pengembangan Sistem Informasi Kepegawaian, Sistem Informasi Penerimaan Siswa Baru dan Sistem Informasi Organisasi dan Manajemen.

2. Strategic merupakan sistem informasi yang penting dan kritis guna mendukung strategi bisnis kesukesan masa depan sekolah, yaitu dengan melakukan pembangunan Sistem Informasi Akademik, ELearning, dan Website, karena ketiga solusi tersebut dapat meningkatkan pengelolaan data-data siswa, modul dan mekanisme pembelajaran sekolah hingga adanya website dapat memberikan kemudahan informasi dan ajang promosi sekolah.

3. Support, merupakan sistem informasi yang penting namun tidak kritis dalam mencapai kesuksesan sekolah. Sistem informasi yang perlu dibangun adalah Sistem Informasi Kerjasama Mitra dimana aplikasi ini dapat melihat potensi lulusan atau alumni untuk bergabung atau bekerja sama langsung dengan partner dunia usaha atau dunia industri. Sistem Informasi Orang Tua, aplikasi ini dapat membantu orang tua dalam memantau nilai akademik anaknya dan adanya transparansi antara sekolah dengan orang tua mengenai kegiatan belajar mengajar di sekolah.

4. High Potential, merupakan sistem indformasi yang mungkin penting untuk mencapai kesuksesan sekolah. Sistem informasi yang perlu dibangun adalah Sistem Informasi Tracer Study digunakan untuk memetakan penyebaran lulusan atau alumni, sehingga mudah melacak dan melakukan kerja sama antara sekolah dan alumni. Sistem Informasi Keuangan dan Pembiayaan, dan Sistem Informasi Sarana dan Prasaran.

Output yang dihasilkan dari metode Ward and Pappard yang dapat menjadi strategi dalam perencanaan bisnis pengembangan SI/TI, meliputi business strategy, IS/IT management strategy, IT strategy, current dan/atau future application portofolio. Berikut ini adalah output Ward and Peppard dari hasil penelitian.

\section{Business Strategy}

Berdasarkan analisis Critical Success Factor (CSF's), SWOT, dan Value Chain yang mendukung metode Ward and Peppard, maka strategi bisnis yang dapat dirumuskan untuk SMK Swasta Torsina dalam perencanaan strategis yaitu SMK Torsina perlu 
menyediakan data lengkap untuk pengelolaan akademik siswa, menyediakan dan menggunakan bahan ajar untuk mendukung KBM, seperti modul, buku pedoman praktik, alat peraga, dan buku panduan terstandar, melakukan rekrutmen tenaga pengajar berdasarkan kompetensi dan keahlian disesuaikan dengan rasio siswa, mengharuskan tenaga pengajar yang telah diterima untuk fokus mengajar pada SMK Swasta Torsina, sekolah perlu menjalin kerjasama dengan mitra kerja penyalur lulusan atau alumni, sekolah harus memfasilitasi peningkatan hardskill dan softskill siswa melalui pendidikan khusus (pelatihan, atau delegasi), secara periodik atau terjadwal menyelenggarakan even atau kegiatan yang mengundang pelajar SMP sederajat sebagai sarana salah satu promosi sekolah, sekolah perlu mengembangkan citra atau image sekolah melalui prestasi dan inovasi serta pemanfaatan sarana prasarana sekolah, secara periodik dan terjadwal melaksanaan diskusi dan sharing dengan orangtua siswa, melakukan pengelolaan manajemen, sarana prasaran, dan keuangan dengan memanfaatkan sistem informasi, secara continue melakukan peningkatan akreditasi sekolah melalui pengelolaan manajemen, sebagai upaya untuk menarik minat calon siswa.

\section{IT strategy, IS/IT management strategy, dan future} application portofolio

Berdasarkan analisis Critical Success Factor (CSF's), SWOT, dan McFarlan Strategic Grid yang mendukung metode Ward and Peppard, maka IT strategy, IS/IT management strategy, dan future application portofolio yang dapat dirumuskan untuk SMK Swasta Torsina yaitu SMK Torsina perlu menerapkan TIK dalam setiap operasional sekolah termasuk proses KBM, perlu membuat sistem informasi akademik siswa yang berisi data lengkap dan history siswa, memberikan pelatihan atau workshop TIK kepada staf dan tenaga pendidik di SMK Torsina, membuat sistem informasi keuangan dan pembiayaan, serta sarana dan prasarana untuk mendukung manajemen sekolah yang sistematis, sekolah perlu menambah komputer dan kapasitas jaringan internet untuk mendukung operasional dan KBM di sekolah, melakukan maintenance dan upgrade sistem informasi yang dibuat secara berkala, menyesuaikan kebutuhan dan kepentingan. Adapun Sistem Informasi (SI) yang perlu dibuat yaitu SI Penerimaan Siswa Baru, SI Kepegawaian, SI Organisasi dan Manajemen, SI Akademik, E-Learning, website sekolah, SI Kerjasama Mitra, SI Orangtua Murid, SI Tracer Study, SI Keuangan dan Pembiayaan, SI Sarana dan Prasarana

\section{KESIMPULAN}

Perencanaan strategis merupakan perencanaan jangka panjang suatu instansi yang bersifat menyeluruh, yang berisi instruksi dan cara dalam pengelolaan sumber daya untuk mencapai tujuan organisasi dalam jangka waktu tertentu. Untuk dapat menyusun perencanaan strategis yang baik diperlukan suatu model, diantaranya adalah Ward and Peppard. Ward and Peppard dapat digunakan untuk perencanaan strategis Sistem Informasi/Teknologi Informasi (SI/TI). Model perencanaan strategis SI/TI Ward and Peppard terdiri dari input dan output. Tahapan input meliputi internal dan external business environment, internal dan external IS/IT environment. Sedangkan output meliputi business strategy, IS/IT management strategy, IT strategy, current dan/atau future application portofolio. Agar Ward and Peppard dapat diterapkan dengan baik, maka diperlukan alat analisis pada proses input model ini, seperti Critical Success Factor's, SWOT Analysis, Value Chain, dan McFarlans Strategic Grid.

Studi kasus pada penelitian ini yaitu SMK Swasta Torsina dengan menggunakan model Ward and Peppard. Perencanaan strategis SI/TI di SMK Swasta Torsina bertujuan agar layanan sekolah, operasional kegiatan, manajerial sekolah menjadi lebih optimal dengan memanfaatkan peran sistem informasi. Output dari penelitian ini berupa business strategy, IT strategy, IS/IT management strategy, dan portofolio sistem informasi yang dipetakan berdasarkan tingkat kepentingannya. Agar output dalam perencanaan strategis SI/TI dapat lebih detail, maka disarankan pada penelitian berikutnya perlu penambahan alat analisis, seperti Porter's Five Force.

\section{REFERENCES}

[1] Macasio, J. Open Practitioner Notes: Information Systems Strategic Planning Basics. Onecitizen. 2009

[2] Wedhasmara A. Langkah-Langkah Perencanaan Strategis 2009;1:14-22

[3] Ward, John dan Joe, Peppard. Strategic Planning for Information System. 3rd ed. England : John Wiley \& Son. 2002.

[4] Ward, John dan Joe, Peppard. Strategic Planning for Information System. 3rd ed. England : John Wiley \& Son. 2002.

[5] Suhartono dan Ngadirun. Penyelenggaraan Program Kelas Unggulan di Sekolah Dasar. Jakarta: Universitas Terbuka. 2009:114

[6] Faslah. Ronny dan Haris. Abdul. "Perencanaan Strategis Sistem Informasi". J. ELTIKOM, Vol. 1 No.1, Hal 31-38, Juni 2017

[7] Juraidin, Nogroho.Eko, dkk. "Pengembangan Rencana Strategis Sistem Informasi dan Teknologi Informasi (Renstra SI/TI) Pada Dinas Kesehatan Kabupaten Bima Menggunakan Model Zachman Framework". Journal of Information Systems for Public Health, Vol. 2, No. 2, Agustus 2017

[8] Robo. Salahudin, Trisno, dkk. "Perencanaan strategis sistem informasi menggunakan Enterprise Architecture Planning pada PT. Karya Cipta Buana Sentosa Maumere". J. Ilmiah Teknologi Sistem Informasi 4 (1) hal 41-48, 2018

[9] Azmi. Muhammad, Soeddijono. Bambang, dkk. "Perencanaan Strategis Sistem Informasi dengan Metode Enterprise Architecture Planning (Studi Kasus: STMIK Syaikh Zainuddin NW Anjani-Lombok)". J. Teknologi Informasi Vol. XIV Nomor 2, Juni 2019

[10] Rudiansyah. "Perencanaan Strategis Sistem Informasi dan Teknologi Informasi STIKES Palembang". J. Digital Teknologi Informasi Volume 2 Nomor 2, 2019

[11] Y. Septiana. "Perencanaan Strategis Sistem Informasi Dengan Pendekatan Ward and Peppard Model (Studi Kasus: Klinik INTI Garut)," J. Wawasan Ilm., vol. 8, no. 1, 2017.

[12] Indriyo Gitosudarmo. Prinsip Dasar Manajemen. BPFE Yogyakarta. Yogyakarta. 1990: 136

[13] Ward, John dan Joe, Peppard. Strategic Planning for Information System. 3rd ed. England : John Wiley \& Son. 2002.

[14] Rahmad. Perencanaan Strategis Pengembangan Sistem Informasi Pada 
Baitul Maal Watamwil Khairul Ikhwan Martapura. Indones J Netw Secur 2016;5:20-5

[15] Freddy Rangkuti. Teknik Membedah Kasus Bisnis Analisis SWOT. Jakarta. Gramedia Pustaka Utama.1998:177

[16] Wedhasmara A. Langkah-Langkah Perencanaan Strategis 2009;1:14-22

[17] Kindangen JG, Bahtiar. Penerapan Analisis Rantai Nilai (Value Chain Analysis) Dalam Rangka Akselerasi Pembangunan Sektor Pertanian di Sulawesi Utara. Semin. Reg. Teknol. Pertan., 2010

[18] L. S. Musianto, "Perbedaan pendekatan kuantitatif dengan pendekatan kualitatif dalam metode penelitian,” J. Manaj. Dan Kewirausahaan, vol. 4, no. 2, pp. 123-136, 2004. 